Supporting Information:

\title{
Probing difference in diffusivity of chloromethanes through water ice in the temperature range of $110-150 \mathrm{~K}$
}

\author{
Jobin Cyriac and T. Pradeep* \\ DST Unit on Nanoscience \\ Department of Chemistry and Sophisticated Analytical Instrument Facility, \\ Indian Institute of Technology Madras, Chennai, India - 600036
}

e-mail: pradeep@iitm.ac.in, fax: +91-44-2257 0509/0545

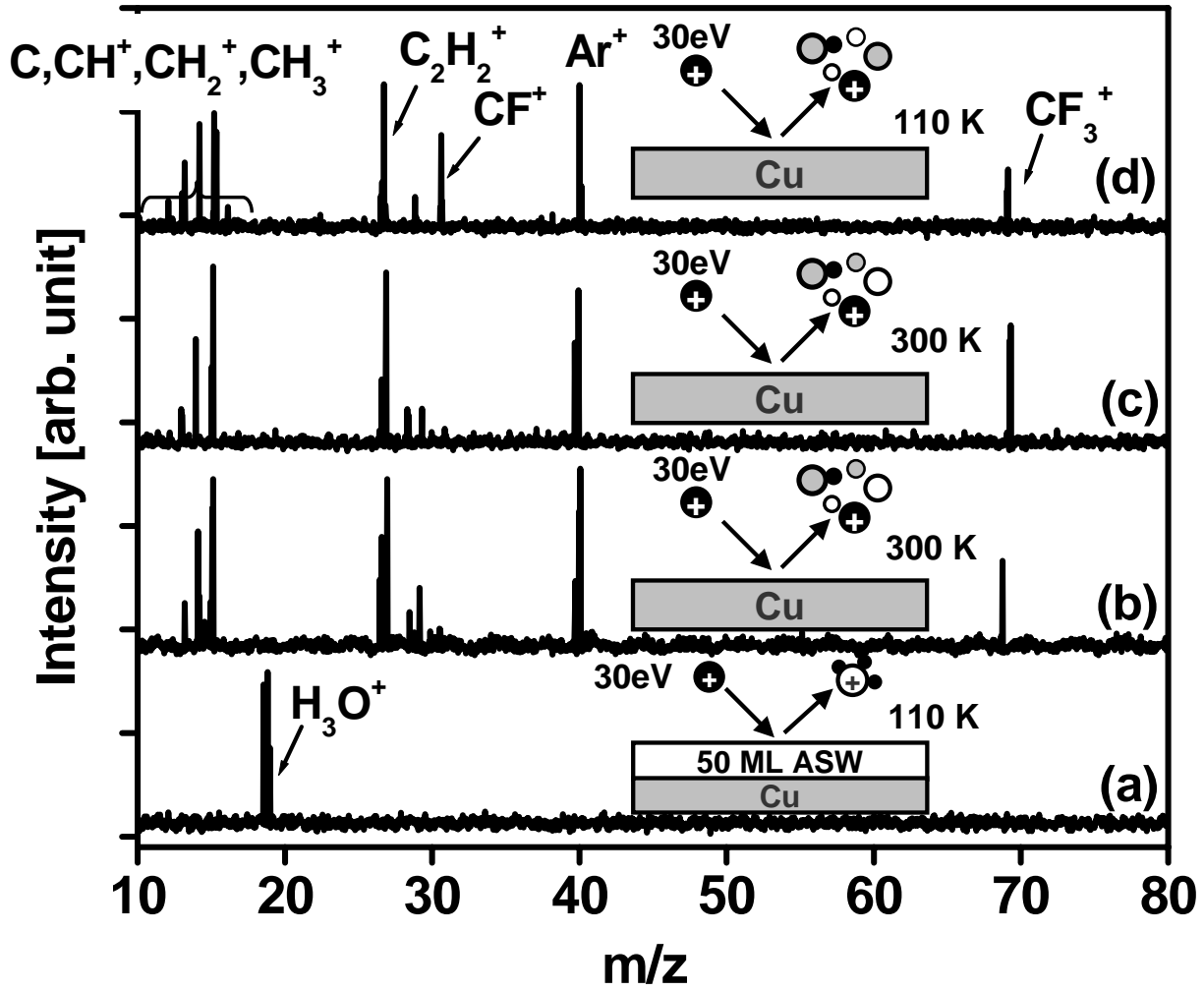

Figure S1. $30 \mathrm{eV} \mathrm{Ar}^{+}$ion sputtering of different surfaces showing the sensitivity of the instrument: (a) shows sputtering of ASW surface into $\mathrm{H}_{3} \mathrm{O}^{+}$ions and (b) data from the copper surface at $300 \mathrm{~K}$ when mass filter is in the RF only mode ie; all ions produced by the El source are colliding on the surface. The data from the same surface at $300 \mathrm{~K}$ and $110 \mathrm{~K}$ when $\mathrm{Ar}^{+}(40 \mathrm{~m} / \mathrm{z})$ is mass selected are given in (c) and (d), respectively. The copper surfaces at room and low temperatures produce sputtering features due to the hydrocarbon film adsorbed on the surface. After the bake-out 
process described in the experimental section, the intensities of these hydrocarbon peaks went below the noise level.

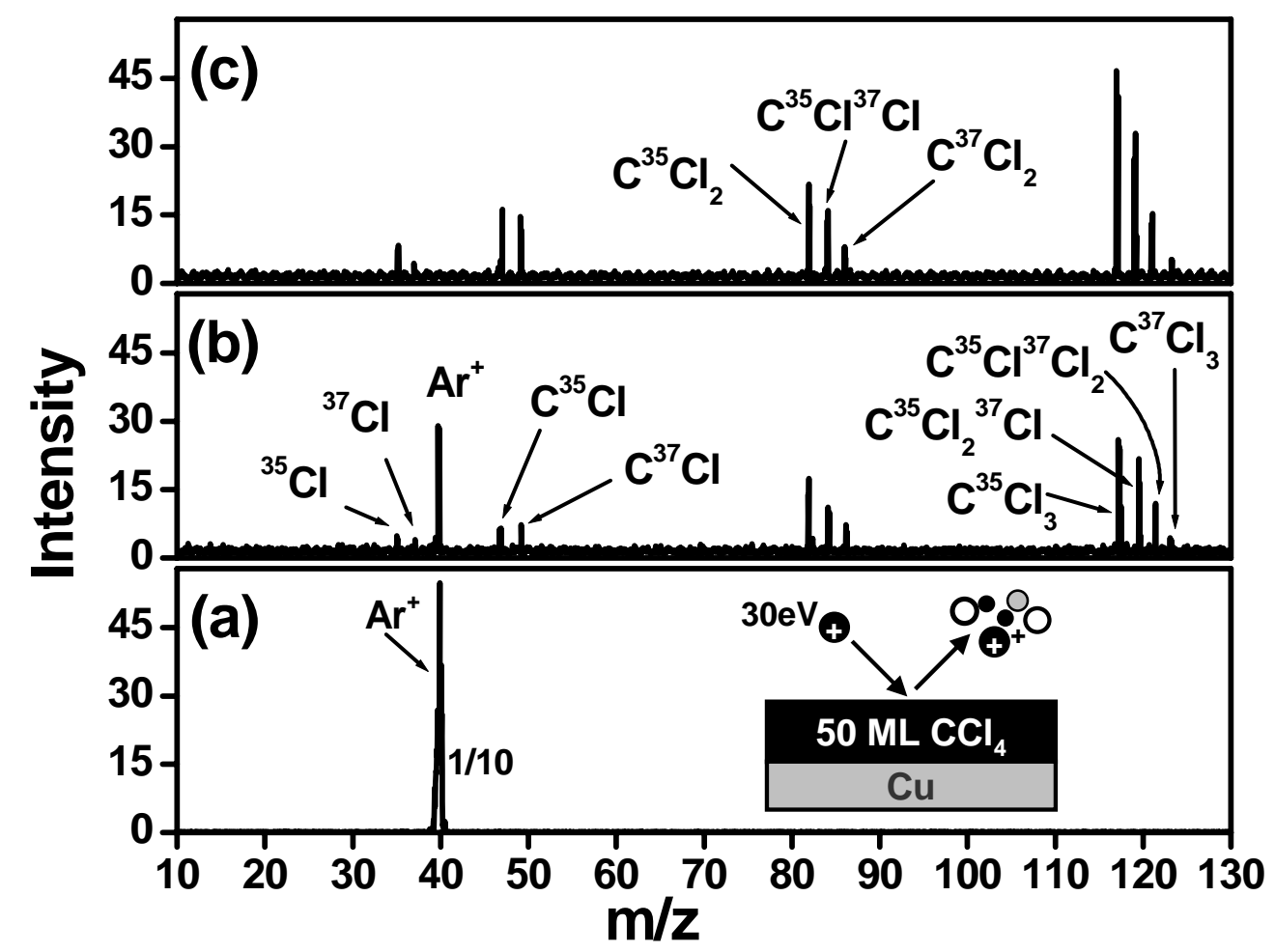

Figure S2: Chemical sputtering spectra of $50 \mathrm{ML} \mathrm{CCl}_{4}$ at three different collision energies; (a) 3 $\mathrm{eV}$, (b) $30 \mathrm{eV}$ and (c) $60 \mathrm{eV}$. Increase in intensity of the sputtered ions is observed as the collision energy is increased from 30 to $60 \mathrm{eV}$.

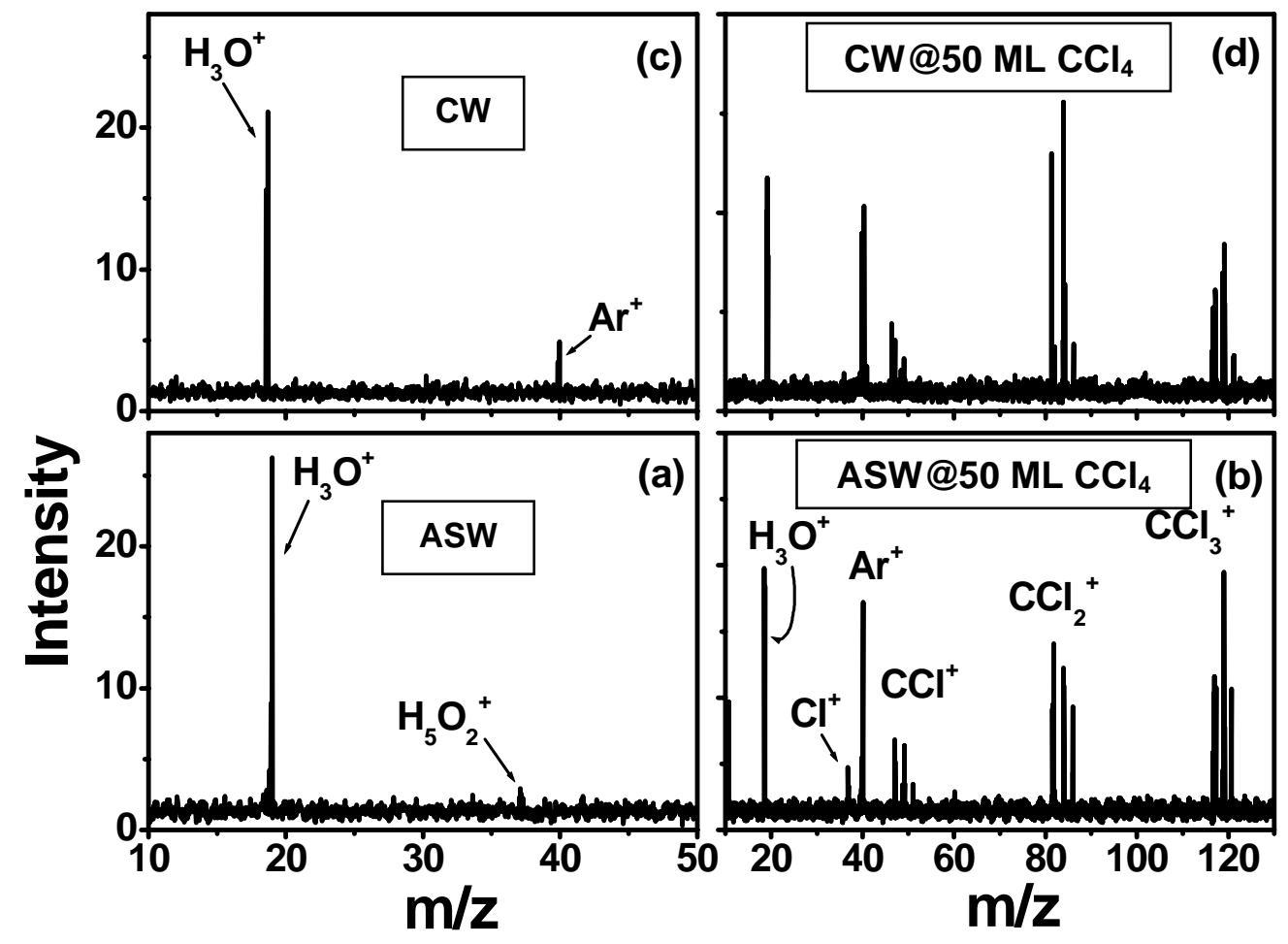


Figure S3. Spectra showing the diffusive mixing of $\mathrm{H}_{2} \mathrm{O}$ molecules through $\mathrm{CCl}_{4}$ overlayers. (a) and (b) are the spectra from ASW and ASW@CCl , respectively. The presence of $\mathrm{H}_{3} \mathrm{O}^{+}$peak after depositing $\mathrm{CCl}_{4}$ shows the transport of $\mathrm{H}_{2} \mathrm{O}$ through $\mathrm{CCl}_{4}$ overlayers. Sputtering spectra from CW and $\mathrm{CW@CCl} 4$ are given in (c) and (d), respectively. Differences between ASW and CW systems are insignificant.

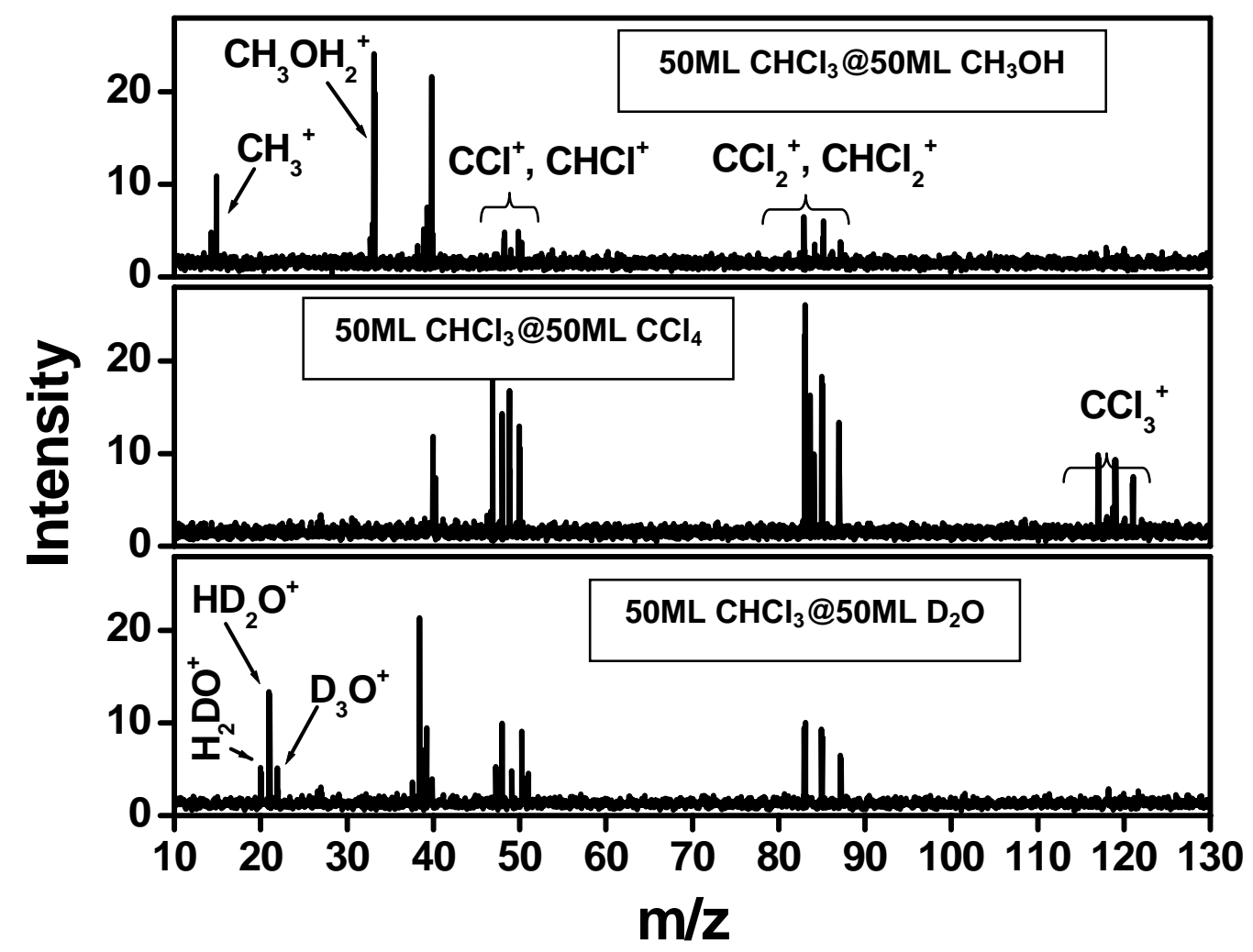

Figure S4. Spectra showing the diffusive mixing of $50 \mathrm{ML}$ of $\mathrm{CHCl}_{3}$ with other molecular solids (a) $\mathrm{D}_{2} \mathrm{O}$, (b) $\mathrm{CCl}_{4}$ and (d) $\mathrm{CH}_{3} \mathrm{OH}$ (thickness is $50 \mathrm{ML}$ for each molecular solid). Collision energy is $30 \mathrm{eV}$ and the projectile is $\mathrm{Ar}^{+}$ion. All spectra contain sputtering features of $\mathrm{CHCl}_{3}$ and thus it is evident that $\mathrm{CHCl}_{3}$ is undergoing diffusive mixing with $\mathrm{D}_{2} \mathrm{O}, \mathrm{CCl}_{4}$ and $\mathrm{CH}_{3} \mathrm{OH}$. The miscibility of $\mathrm{CHCl}_{3}$ in $\mathrm{CCl}_{4}$ is more compared to the other two, as seen from the more intense $\mathrm{CHCl}_{3}$ features in this case. 


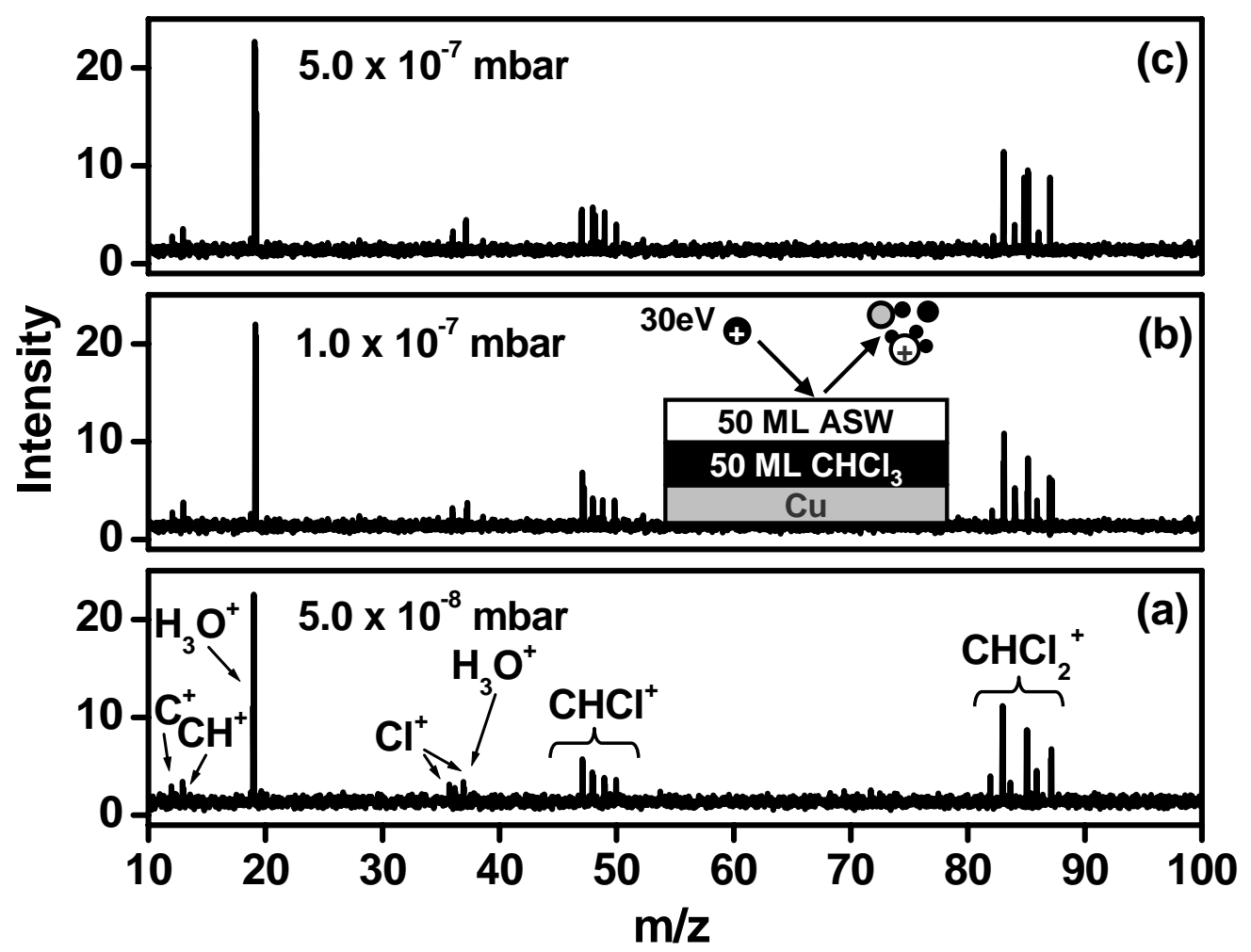

Figure S5. (a), (b) and (c) are the $\mathrm{Ar}^{+}$induced chemical sputtering spectra from $50 \mathrm{ML}$ $\mathrm{CHCl}_{3} @ 50 \mathrm{ML}$ ASW surface where upper ASW layer is prepared at three different deposition pressures. It is clear from the intensities of the sputtered peaks that the composition of the surface did not vary with the change in deposition rate of ASW and the thickness of the ASW layer is comparable. 